\title{
A Construção Narrativa da Identidade
}

\author{
Narrative Construction of Identity
}

\author{
André Guirland Vieira \& Margarida Rangel Henriques* \\ Universidade do Porto, Porto, Distrito do Porto, Portugal
}

\begin{abstract}
Resumo
Este artigo tem como objetivo apresentar a perspectiva da construção narrativa do self e da identidade a partir da Psicologia Socio-histórica de L. S. Vygotsky, mostrando seu desenvolvimento na Psicologia Cultural, particularmente nos escritos de Jerome Bruner até autores contemporâneos, com destaque para os trabalhos de Hubert Hermans, Dan McAdams, Tilmann Habermas e Robyn Fivush. O conceito de self narrativo aparece como desenvolvimento do paradigma narrativo e como uma importante contribuição ao estudo da internalização das funções psicológicas superiores e à compreensão da construção do sujeito sócio-histórico. A identidade, como espaço de construção do sujeito psicológico parece ser um lócus privilegiado onde podemos observar o funcionamento do paradigma narrativo em termos de negociação de significados entre os acontecimentos biográficos e o indivíduo.

Palavras-chave: Narrativa, identidade, self dialógico, histórias de vida.
\end{abstract}

\begin{abstract}
This paper aims to present the narrative construction of the self and the identity from the perspective of Vygotsky's Socio-historical Psychology. It also shows the development of narrative construction in Cultural Psychology, particularly in the writings of Jerome Bruner up to contemporary authors, highlighting the work of Hubert Hermans, Dan McAdams, Tilmann Habermas and Robyn Fivush. The concept of the narrative self appears as a development of the narrative paradigm and as an important contribution to the study of the internalization of higher psychological functions and to the understanding of the construction of the socio-historical subject. The identity as a space for the construction of the psychological subject seems to be a privileged place where we can observe the development of the narrative paradigm in terms of negotiation of meaning between biographical events and the individual.

Keywords: Narrative, identity, dialogical self, life stories.
\end{abstract}

\begin{abstract}
A abordagem narrativa do self e da identidade consolidou-se recentemente no campo da psicologia a partir dos escritos de Hermans e Kempen (1993) e McAdams (2001). Ela tem como princípio a ideia de que a história contada por uma pessoa acerca de sua vida pode ser tomada como um retrato de seu próprio self $\mathrm{e}$ de sua identidade. Em uma abordagem narrativa, os conceitos de identidade e self aparecem muito próximos um do outro. McAdams (2001) faz questão de marcar a diferença, na medida em que concebe identidade como uma qualidade do self, isto é, como "uma configuração integrativa do self no mundo adulto" (p. 102). A identidade é aqui definida como a integração sincrônica e diacrônica do self capaz de situar a pessoa em algum nicho psicossocial e dar um mínimo de propósito e sentido a sua vida. Em Hermans e Kempen (1993) identidade e
\end{abstract}

\footnotetext{
* Endereço para correspondência: Faculdade de Psicologia e Ciências da Educação, Universidade do Porto, Rua Alfredo Allen, Porto, Portugal 4200-135. E-mail: agvieira2010@gmail.com e mrangel@fpce.up.pt
}

self aparecem aglutinados no conceito de self formulado por William James (1890). James concebe o self como organizado em torno de um sujeito que conhece (ou $I$ ) e um objeto que se dá a conhecer (ou Me). As características do $I$ são a continuidade, a diferenciação e a volição. A continuidade é caracterizada por um senso de identidade pessoal constante através do tempo, a diferenciação pelo sentimento de individualidade e singularidade, enquanto que a volição o é pelo sentimento de capacidade de escolha. Por outro lado, o self como Me é composto por todos aqueles elementos que considero como pertencentes a mim, não apenas meu corpo ou minhas qualidades psicológicas, mas também os meus amigos, meus inimigos, minha posição social ou meus bens (Hermans, 2001). Self e identidade aparecem aqui aglutinados tanto no sentimento de unidade e constância que caracterizam o $I$ como na multiplicidade de autoimagens que compõem o $M e$.

Neste artigo apresentamos a perspectiva da construção narrativa do self e da identidade a partir da Psicologia Socio-histórica de Vygotsky (1929/2000), mostrando seu desenvolvimento na Psicologia Cultural, particularmente 
nos escritos de Jerome Bruner (1987) até autores contemporâneos, com destaque para Hermans e Kempen (1993), Fivush (2008), Habermas (2007) e McAdams (2001). O desenvolvimento do paradigma narrativo (Brockmeier \& Harré, 2003) não se deu, entretanto, de uma forma cronologicamente linear. Embora a inspiração em Vygotsky (1991) seja uma marca da Psicologia Cultural, traduções recentes de textos, como a do manuscrito de 1929 que utilizamos a seguir, reforçam ideias já desenvolvidas, contribuindo para a construção do conceito de self e de identidade narrativa a partir de pontos de vista não antes abordados de forma tão precisa. Seguimos, portanto, o percurso desde a Psicologia Cultural de Bruner, retornando a seguir a Vygotsky (1929/2000), para só então avançarmos até os autores contemporâneos.

\section{Self e Narrativa}

Para Bruner (1997), os seres humanos constroem significado a partir dos sistemas simbólicos já dados na cultura. Estes sistemas simbólicos constituem uma espécie de kit de ferramentas que os homens utilizam para construir suas representações do mundo. A narrativa é uma dessas ferramentas: "filosoficamente falando, meu ponto de vista em relação à narrativa é construtivista - uma visão que tem como premissa que a principal função da mente é a construção do mundo, quer seja através das ciências ou das artes" (Bruner, 1987, p. 11). A ideia da narrativa como ferramenta na construção da representação do mundo parte da concepção de Kant (1781/1985) de que, enquanto o espaço é a forma de nossa experiência exterior, o tempo é a forma de nossa experiência interior. Além de Kant, Bruner toma Ricoeur (1994), quem propõe que a representação humana do tempo só pode se dar na forma de uma narrativa. A partir daí, Bruner (1987) irá postular duas teses.

A primeira tese é a seguinte: nós não temos outra maneira de descrever o tempo vivido a não ser na forma de uma narrativa. ... Minha segunda tese é a de que a mimesis entre o que chamamos de vida e a narrativa é uma via de mão dupla: isto é, assim como a arte imita a vida, no sentido de Aristóteles, assim, como propõe Oscar Wilde, a vida imita a arte. Narrativa imita a vida, vida imita a narrativa. Vida, neste sentido, é o mesmo tipo de construção da imaginação humana do que a narrativa. Ela é construída pelos seres humanos a partir de um raciocínio ativo, através do mesmo tipo de raciocínio a partir do qual nós construímos as narrativas. (Bruner, 1987, pp. 12-13)

A representação de nossa experiência de vida é, portanto, uma narrativa, e nós utilizamos a narrativa como uma ferramenta, a fim de organizar nosso contato com o mundo em termos de uma experiência inteligível.

O coração do meu argumento é o seguinte: eventualmente os processos linguísticos e cognitivos moldados culturalmente que guiam a autoprodução das narrativas de vida assumem o poder de estruturar a experiência perceptiva, de organizar a memória, de segmentar ou unir os diversos eventos de uma vida. No final, nós nos tornamos as narrativas autobiográficas através das quais nós contamos nossas vidas. E dado à conformação cultural a qual eu referi, nós também nos tornamos variantes das formas culturais canônicas. (Bruner, 1987, p. 15)

Segundo este ponto de vista da Psicologia Cultural o self é o resultado de um processo de construção de significado. O self não é um núcleo isolado de consciência contido em nossa cabeça, mas é construído interpessoalmente. Ele é definido em termos de significados tanto pessoal como coletivos ambos em maior ou menor grau definidos pela cultura. Cada cultura possui uma representação do que significa pessoalidade, de modo que o significado do self é negociado entre o indivíduo e a cultura na qual ele está inserido. Nesta negociação observamos a função do kit de ferramentas de que nos fala Bruner (1987), o indivíduo constrói narrativas sobre si mesmo a partir de narrativas culturalmente dadas: tragédias, comédias, novelas, romances ou bildungsroman, nas quais ele assume o lugar de protagonista em um processo de autoconstrução. Essas narrativas possuem, portanto, uma função organizadora do self. A vida também imita a arte.

\section{A Personalidade Organiza-se como um Drama Sociocultural}

A noção de uma construção narrativa do selfjá aparece nos escritos de Vygotsky (1929/2000) em torno da ideia de que a personalidade está organizada como um drama. $\mathrm{O}$ ponto de partida é o princípio fundamental de que "tudo o que é interno nas funções superiores ter sido externo: isto é, ter sido para os outros o que agora é para si” (p. 24). Vygotsky toma o exemplo da psicogênese do gesto indicativo: originalmente um movimento de agarrar mal sucedido dirigido a um objeto, em um segundo momento a mãe o significa como uma indicação e finalmente a criança passar a indicar. A expansão desse modelo leva-o a propor que "qualquer função psicológica foi externa - foi social, antes de se tornar função foi relação social entre duas pessoas" (p. 24). De modo que "a natureza psicológica da pessoa é o conjunto das relações sociais transferidas para dentro e que se tornaram funções da personalidade e formas de sua estrutura" (p. 27). Através dos outros constituímo-nos. O que hoje chamamos raciocínio fora outrora discussão, o modelo do pensamento (conversa consigo mesmo) é o diálogo. Isso leva Vygotsky a construir uma lei geral: "qualquer função no desenvolvimento cultural da criança aparece em cena duas vezes, em dois planos - primeiro no social, depois no psicológico, primeiro entre as pessoas como categoria interpsicológica, depois dentro da criança" (1929/2000, p. 26).

A interiorização das relações interpessoais irá, portanto, constituir a base da estrutura social da personalidade. O que era relação torna-se função psicológica. Mas as 
funções psicológicas não apenas se constituem nas relações interpessoais, elas também determinam o modo como as funções relacionam-se entre si dentro de uma mesma personalidade. $\mathrm{O}$ que foi uma vez interação social entre pessoas tornar-se-á, após o processo de interiorização, interação entre as funções psicológicas superiores. De maneira análoga às relações interpessoais, tais funções personificam-se, o que leva Vygotsky (1929/2000) a pensar que a melhor maneira de representá-las e de estudá-las é na forma de um drama.

O conceito de self organizado como um drama torna-se mais complexo, assumindo uma dimensão efetivamente sociocultural. O drama está repleto de conflitos únicos, impossíveis de serem encontrados na dimensão dos sistemas orgânicos, mas apenas nos socioculturais. "O drama sempre é a luta de tais ligações (dever e sentimento; paixão, etc.)" (Vygotsky, 1929/2000, p. 35). O drama é um "choque dos sistemas" (p. 35), representados pelos diferentes papéis sociais, ideias, sentimentos e paixões atuados e vividos por uma mesma pessoa. Tais sistemas-papéis, no momento em que são personificados representam pontos de vista divergentes em atuação dentro de uma mesma personalidade, de maneira que "a dinâmica da personalidade é o drama" (p. 35). A psicologia do selfé, portanto, uma psicologia de papéis organizados em uma hierarquia socialmente dada, mas passíveis de entrarem em conflito no momento em que essa ordem se desestabiliza. Vygotsky toma o exemplo do conflito de um juiz com sua esposa: em um primeiro sistema, no complexo profissional, onde ele ocupa a posição de juiz há a condenação; no segundo sistema, no complexo da família onde ocupa a posição de marido, sabe que ela é má, mas por amá-la a perdoa.

A visão de Vygotsky (1929/2000) aproxima-se da noção contemporânea de self dialógico, tal como proposta por Hermans e Kempen (1993), na qual diferentes posições do $I$ dialogam entre si. Uma diferença, é que Vygotsky antevê que tal organização da personalidade necessita de um sistema de autorregulação. Curiosamente, o modelo de autorregulação proposto por Vygotsky é o do sonho, tal como relatado na história do sonho do chefe da tribo africana dos Kaffirs: o que o chefe verá em sonho é o que irá fazer. "A relação sonho: conduta futura (função reguladora do sonho) reduz-se geneticamente e funcionalmente à função social (mago, conselheiro dos magos, intérprete dos sonhos, alguém que joga na sorte - sempre dividido em duas pessoas). Depois se une em uma pessoa" (1929/2000, p. 32).

Aqui, a função social do sonho como um sistema adivinhatório constrói o sonho como função psicológica que regula a conduta futura. Assim, o chefe organiza seu plano de ação, o qual dirige o destino de toda a tribo, a partir do que aparecer em seu sonho. O sonho passa a dirigir as ações e a atuar como um regulador da personalidade. Vygotsky toma o sonho do chefe dos Kaffirs como exemplo de modelo regulador e coloca à psicologia a tarefa da investigação de mecanismos semelhantes.

\section{O Self como uma Multiplicidade Dialógica}

A noção de uma construção socio-histórica e cultural do self ganha com Hermans e Kempen (1993) uma nova dimensão. Sua concepção dialógica do self reúne os conceitos anteriormente desenvolvidos na psicologia e organiza-os, por assim dizer, em uma teoria da personalidade, a I-positioning theory. A partir dos estudos de Markus e Wurf (1987) sobre o caráter multifacetado do self; de Martindale (1980) sobre a teoria dos sub-selves; de H. Murray (1938) e de Jung (1909/1995) sobre os complexos; de McAdams (1985) sobre imago; de G. H. Mead (1934) e principalmente as proposições sobre o self de M. Bakhtin (1973) e W. James (1890), Hermans e Kempen (1993) concebem o self, não como uma unidade, mas como uma multiplicidade. O self passa a ser entendido como organizado na forma de uma novela polifônica. A metáfora do self como uma novela polifônica expande a ideia original de W. James do self dividido em um sujeito/autor $(I)$ e um objeto/ator $(\mathrm{Me})$. Segundo Hermans e Kempen o indivíduo vive em uma multiplicidade de mundos, cada mundo com seu próprio autor, cada autor com um ponto de vista relativamente independente em relação aos outros autores. "Isto significa assumir que o indivíduo consiste de uma multiplicidade de autores em uma mútua relação dialógica, criando, assim, uma organização mais complexa do self" (p. 213). Com base na qualidade polifônica do self, Hermans e Kempen (1993) propõem o conceito de self dialógico, definido como "uma multiplicidade dinâmica de posições do ' $I$ ' relativamente autônomas em uma paisagem imaginária" (p. 215). Da mesma forma que em uma paisagem real, o $I$ pode mover-se de um lugar (posição) a outro, de acordo com as mudanças na situação e no tempo. O I é ainda capaz de dotar imaginariamente cada posição com uma voz, de maneira que relações dialógicas entre as posições possam ser estabelecidas. As diferentes vozes relacionam-se umas com as outras, tal como personagens em uma história, resultando em um self complexo e narrativamente estruturado.

O conceito de self dialógico está baseado no pressuposto de que a outra pessoa não está somente fora, sendo simultaneamente uma parte constitutiva do próprio self. O self dialógico pode ser compreendido somente no momento em que o intercâmbio social e a intersubjetividade forem concebidos como intrínsecos a sua natureza. Aqui a imaginação adquire um papel preponderante. Segundo Hermans (2008) é uma ilusão pensarmos que não vivemos, em grande parte, em um mundo imaginário. Nosso mundo está repleto de figuras midiáticas, réplicas imaginárias de amores, parentes ou amigos, bem como de figuras extraídas dos sonhos e outras fantasias com as quais mantemos diálogos imaginários. Mesmo quando estamos em silêncio, encontramo-nos em comunicação com estas figuras imaginárias. Esses diálogos imaginários têm um papel central em nossa vida cotidiana, interferindo em nossos relacionamentos com os outros, eles constituem uma parte 
essencial de nossa construção narrativa do mundo. "A imaginação traz os outros para dentro do self, onde eles têm um papel constitutivo na criação de significados" (p. 187). Diálogos imaginários e interações reais existem lado a lado, de modo que "o outro no self pode ser considerado como uma parte da vida cotidiana" (p. 188).

O self é deste modo concebido como uma multiplicidade dinâmica de I-positions relativamente autônomos.

Tais "I-positions" podem ser partes de um domínio interno do self, tal como o " $P$ " como ambicioso, o " $P$ " como vulnerável, o " $P$ " como filho de meus pais, mas também podem referir-se a outros significativos como partes do domínio externo do self, tais como "meus pais", "meus filhos", "meus amigos" e mesmo "meu oponente". (Hermans, 2008, p. 188)

Os I-positions internos e externos estão envolvidos em um processo contínuo de negociação e intercâmbio, de maneira que o $I$ está sempre ligado a uma posição contextualizada no tempo e no espaço. $\mathrm{O} I$ tem a capacidade de flutuar entre as diferentes posições e na medida em que dota cada posição com uma voz, cria uma relação dialógica entre elas. As vozes comportam-se como caracteres interativos que, como em uma história, discutem entre si, concordando ou discordando uns com os outros. As I-positions "não devem ser entendidas como centros estáveis de conhecimento, mas como perspectivas que variam no intercâmbio direto com o meio social" (Hermans, 2008, p. 193), de maneira que o self pode ser entendido como um sistema. Este é o ponto de partida do estudo de Valsiner (2002), o self, tal como proposto na I positioning theory, é um sistema e, como tal, tem de possuir uma função autorreguladora que atenda à necessidade de manter uma estabilidade dinâmica entre suas partes, de maneira que o próprio sistema seja mantido como uma unidade. A solução proposta por Valsiner é simples: a própria dialogicidade é capaz de cumprir este papel. Como propriedade geral dos sistemas, a dialogicidade atende a uma necessidade central de manter uma estabilidade dinâmica dentro do próprio sistema, de maneira que o selfé capaz de manter-se unido em torno do contínuo diálogo entre as diferentes vozes que o compõem. Enquanto houver diálogo o self manter-se-á unido. Valsiner retoma aqui a necessidade, proposta por Vygotsky (1929/2000), de uma autorregulação dentro da personalidade, acrescentando um importante elemento na teoria do self dialógico. A I-positioning theory dá, assim, um passo à frente no entendimento do processo de internalização das funções psicológicas superiores (Vygotsky, 1991). Ela clarifica o mecanismo através do qual a pessoa relaciona-se com a sociedade, negociando com ela papéis sociais de uma forma ativa e em um processo de construção de si mesmo.

\section{A Personalidade é Construída Historicamente: Narrativas de Vida e Identidade Narrativa}

Faz-se necessário retomarmos a advertência de Wertsch, Del Rio e Álvarez (1995) de não nos esquecermos do aspecto histórico na abordagem sociocultural da psicologia, pois a construção do self também envolve uma dimensão histórica. Em nossa própria cultura as visões do self são moldadas e sustentadas pela história de nossas religiões, pelo humanismo renascentista, tanto quanto pela economia ou pela língua. Mas assim como a construção do self depende de uma história social, ela também depende de uma história pessoal e familiar, as quais aparecem como que embutidas na primeira. Ou, visto a partir do ponto de vista do indivíduo, a história cultural aparece como pano de fundo no qual se desenrola a trama da construção autobiográfica do self. $\mathrm{O}$ aspecto histórico na construção do self aparece em Bruner (1997) e Valsiner (1989), que apontam para a dependência de sua construção em relação à história de vida pessoal. Tal aspecto é desenvolvido mais recentemente por Dan McAdams $(1985,2001)$.

McAdams $(1985,2001)$ toma como ponto de partida a proposição de Erikson (1968) de que o desenvolvimento de uma história de vida é um marco no processo de aquisição de uma identidade psicossocial madura. A adolescência seria o momento do desenvolvimento humano no qual convergem as habilidades cognitivas construídas ao longo da infância para produzir uma narrativa autobiográfica coerente (Fivush, 2008; Fivush \& Baker-Ward, 2005; Fivush \& Buckner, 1998; Fivush \& Haden, 2003) e as demandas socioculturais para um posicionamento dentro da sociedade (Erikson, 1968; Habermas, 2007; Habermas \& Bluck, 2000), as quais culminam na necessidade e na possibilidade de construção de uma identidade socioculturalmente situada. Segundo McAdams $(1985,2001)$ essa identidade organiza-se na forma de uma história de vida. Na adolescência as pessoas, em nossa sociedade moderna, iniciam um processo de revisão do passado, compreensão do presente e planificação do futuro a partir da elaboração de narrativas autobiográficas, as quais têm uma função de construir um mínimo de unidade e propósito a suas próprias vidas e ao mundo. As histórias de vida são coconstruídas com as pessoas que a cercam, bem como com o contexto sociocultural no qual elas vivem. Essas histórias situadas, para utilizar o termo cunhado por McLean, Pasupathi e Pals (2007), são não apenas o que constroem e mantêm, mas também a própria forma da identidade de seu autor. Tais narrativas têm a função de construir uma configuração integrativa do self no mundo adulto. Elas têm a capacidade de integrar diacronicamente os diferentes episódios e situações de vida vividas ao longo dos anos em histórias carregadas de sentido. Elas têm também a capacidade de organizar as crenças e posicionamentos diante da vida em termos de um processo de mudança e transformação: antes pensava e agia de tal modo, enquanto que hoje penso e ajo diferente. As histórias de vida têm também uma função de integração sincrônica, organizando os diferentes papéis sociais, as diversas formas de relacionamento, os sentimentos e pensamentos, de maneira que eles possam ser vistos e entendidos como partes da mesma configuração do self. 
Vieira, A. G. \& Henriques, M. R. (2014). A Construção Narrativa da Identidade.

Segundo o modelo de McAdams $(1985,2001)$ a identidade não pode ser vista como sinônimo de self, self-concept ou "como aquele que eu sou", mas como uma qualidade particular a partir da qual as pessoas entendem a si próprias ou como uma maneira através da qual o self pode ser organizado ou configurado.

Na medida em que o autoentendimento de uma pessoa está integrado sincronicamente e diacronicamente, de modo que ela possa se situar de maneira significativa em algum nicho psicossocial e possa prover sua vida com algum grau de unidade e propósito, esta pessoa tem identidade. (McAdams, 2001, p. 102)

Identidade não é, portanto, algo que emerge na adolescência de maneira acabada, mas está sempre sendo construída e reconstruída. Ela pode ser entendida como uma narrativa aberta, nunca totalmente concluída, ou como uma antologia de histórias mais ou menos integradas e coerentes acerca da vida de uma pessoa. O caráter distintivo dessas narrativas é sua tendência à unidade $\mathrm{e}$ à coerência.

Segundo McAdams (2001) a identidade não é uma aquisição pessoal, mas um trabalho junto e dentro da cultura. As histórias de vida são textos psicossociais coconstruídos pelo indivíduo e pela cultura, a partir da qual ele retira um sentido para sua própria vida. As histórias de vida refletem os valores e as normas das sociedades dentro das quais elas foram construídas (Fivush, 2008; McLean et al., 2007; Pasupathi, 2001). Por outro lado, a cultura provê um menu de modelos a partir dos quais as histórias de vida e a identidade são construídas (Adler \& McAdams, 2007; Fivush, 2008; Habermas, 2007). Fivush (2008) propõe que embora as narrativas dos eventos passados forneçam os tijolos para a construção da história de vida, a qual organiza esses eventos de maneira que eles possam ser avaliados e compreendidos, a forma das narrativas é culturalmente construída. Em primeiro lugar, as culturas definem o modelo de vida, quer na forma de life scripts (Bernsten \& Rubin, 2004) ou de biografias culturalmente canônicas (Habermas \& Bluck, 2000). As culturas definem os períodos do desenvolvimento humano, tais como infância, maturidade, velhice em termos dos eventos apropriados a cada um deles: educação, casamento, gravidez, etc. Esses scripts são atuados e incorporados pelas pessoas em atividades culturalmente mediadas, como a escola ou o trabalho (Fivush, 2008).

Exemplos desses modelos são apresentados por Delory-Momberger (2004) e McAdams (2006). McAdams observou uma progressão típica de episódios em narrativas culturalmente situadas, as quais ele definiu como redemptive self. Trata-se de um modelo narrativo tipicamente norte-americano encontrado desde as autobiografias puritanas até os filmes de Hollywood, nas quais um inocente protagonista dotado com convicções simples, porém fortes, enfrenta um mundo perigoso, vencendo desafios e adversidades com o objetivo de redimir a si mesmo e ao mundo. Em consonância com McAdams,
Delory-Momberger mostra, a partir dos trabalhos de Sennett (2000), a ocorrência de uma mudança na forma das autobiografias dos norte-americanos desde 1970 até os dias de hoje. Enquanto na década de setenta as autobiografias possuíam uma linearidade orientada por uma trajetória profissional dentro de uma empresa ou instituição, hoje se modificaram, tornando-se muito mais fragmentárias. Segundo a autora, o processo de subjetivação que caracteriza a sociedade individualizada contemporânea se traduz por uma cultura heroica do sujeito, que atribui a cada um a responsabilidade pela construção de seu próprio percurso, tanto profissional como pessoal ou de sua própria identidade. "Cada indivíduo deve, no seu trabalho, lazer ou vida afetiva se comportar como um verdadeiro profissional de sua própria performance" (p. 4), de maneira que é exigido que ele se torne um empresário de si mesmo.

Outra faceta do modelo de McAdams (2004, 2005) é o objetivo de investigar como e porque os indivíduos diferenciam-se uns dos outros. A partir de uma revisão da literatura, Hooker e McAdams (2003) e McAdams $(2001,2005)$ identificaram três abordagens mais comuns à Psicologia da Personalidade: a dos traços disposicionais, estudados como tendências comportamentais ou como hereditariedade; das características de adaptação, como motivação, papeis sociais, crenças, estratégias de coping, mecanismos de defesa entre outros; e as psicobiografias e histórias de vida. McAdams organiza estas abordagens em níveis, desde a mais constante (os traços) até a menos constante (as histórias de vida). A construção da singularidade do indivíduo depende de todos esses níveis, mas é na história de vida que ela aparece de forma mais compreensível como a interpretação subjetiva das experiências passadas unida à integração seletiva dos aspectos culturais onde o indivíduo vive (McAdams, 2004). Na história de vida encontram-se reunidos tanto os traços disposicionais e as características de adaptação, como os eventos singulares à trajetória de vida do sujeito e a história sociocultural na qual ele está inserido. Seguindo os passos de Giddens (1991) e de Tomkins (1979), McAdams propõe que a história de vida passe a ser entendida como a própria identidade da pessoa. A identidade não será, portanto encontrada no comportamento, mas na narração da própria vida. Tal narrativa pode ser analisada em termos dos cenários, temas, ações, intriga, personagens, imagos, tonalidade emocional, complexidade de estrutura entre outras possibilidades.

\section{Conclusão}

O estudo da identidade narrativa envolve, portanto, um aspecto temporal e um espacial (Hermans, 2001). $\mathrm{O}$ aspecto espacial é atualmente mais cuidadosamente trabalhado pela abordagem de Hermans da multiplicidade de vozes em um self narrativo, embora ela também apareça em McAdams (1993) no estudo das imagos e dos diferentes caracteres dos personagens da narrativa. 
É importante salientar que o conceito de caráter aparece já em James (1890), tendo sua origem na Poética de Aristóteles (trad. 1992). A perspectiva aristotélica de caráter também pressupõe a incorporação dos aspectos culturais dos personagens à narrativa (Ricoeur, 1994). Os homens bons têm de agir de acordo com o que é esperado deles, assim como os maus ou as mulheres, de modo que possa ser construída uma verossimilhança: a arte imita a vida. O jogo entre os caracteres constrói a dialogicidade narrativa em uma representação da ação humana. Aqui temos uma importante contribuição da abordagem narrativa à psicologia do desenvolvimento: o retorno da subjetividade via imaginação (Salgado \& Hermans, 2005). Se isto aparece de forma incipiente nas anotações de Vygotsky (1929/2000), o é desenvolvido e complexificado nos trabalhos de Hermans (2001) e McAdams (2001). A diferença entre ambos é que enquanto Hermans analisa os personagens da narrativa em sua diversidade de caracteres (um personagem pode ter mais de um caráter) e atuação em um ou mais cenários, McAdams exige que essa narrativa deva se desdobrar em uma história de vida. Em ambos a narrativa aparece como uma construção imaginada do self. Tanto em McAdams como em Hermans o self é construído na linguagem e em uma relação intersubjetiva entre os seres humanos, contextualizada na cultura. É importante ressaltar que o self dialógico só ganha existência no momento em que é narrado, mesmo que a narrativa seja endereçada a um outro imaginário. Por outro lado, o relato de uma história de vida depende em grande parte do interlocutor a quem ela se dirige. Há aqui uma nítida herança, não apenas de Vygotsky, mas também de Bakhtin (1973) e Wittgenstein (1991), no momento em que a mente não pode ser entendida senão como uma construção intersubjetiva, a qual é objetivada através linguagem partilhada por uma determinada cultura. A mente só revela sua existência através da linguagem. Do mesmo modo como é impossível haver uma linguagem privada, assim é até certo ponto impossível haver uma mente privada. O que há de privado na mente é construído pela diversidade de histórias, tanto do corpo, via hereditariedade, como da história de vida, a qual engloba tanto os aspectos sociais, culturais, familiares e pessoais de um determinado sujeito (Hooker \& McAdams, 2003). A imaginação aparece não apenas como elemento fundamental na elaboração das histórias de vida, como na construção dos personagens com os quais nos identificamos ou aos quais nos opomos. Esses personagens atuando em diversos cenários são os elementos constitutivos das narrativas que compõem nossa identidade. A imaginação não é aqui algo que se opõe à realidade, mas uma ferramenta de interiorização ativa da própria realidade. A imaginação aparece como um elemento fundamental no processo de interiorização das funções psicológicas superiores tal como proposto por Vygotsky (1991). Seguindo a perspectiva de Hermans, salientamos que as abordagens espaciais e temporais da narrativa são complementares e absolutamente necessárias à compreensão de sua complexidade.

$\mathrm{O}$ aspecto temporal é atualmente investigado mais acuradamente por Fivush (2008), Habermas, Ehlert-Lerche e de Silveira (2009) e McAdams (2001). Estes modelos enfatizam a tendência integrativa da identidade narrativa. Ela é capaz de integrar diferentes experiências e tendências divergentes em uma ou mais narrativas mais ou menos congruentes. Tal integração não ocorrerá, entretanto, em uma única narrativa de vida, mas em diversas histórias acerca de si mesmo, algumas mais inteiras e coerentes, outras mais fragmentadas, de maneira que a identidade narrativa poderá ser mais propriamente definida como uma "antologia do self" (McAdams, 2001, p. 117).

A noção de antologia em McAdams (2001) conduz novamente o conceito de self para a multiplicidade e a dialogicidade. Em uma antologia de histórias, diversas versões concorrem entre si, concordando em alguns aspectos e discordando em outros. Se partirmos do princípio que a construção da identidade pressupõe a elaboração de narrativas integradoras, podemos imaginar essas versões dialogando entre si na tentativa de produzir um sentido coerente. Parece, portanto, haver uma unanimidade em torno do caráter polifônico do self narrativo. Outro ponto comum aparece em torno do caráter social do self. É impossível pensar um self narrativo à parte de todas as histórias contadas sobre ele, sejam elas canônicas ou não. Como muito bem ressaltou Fivush (2008), a organização do self pode até se dar em oposição a essas histórias, mas jamais em sua ausência.

História e linguagem são dois elementos fundamentais à construção narrativa da identidade. É através da narrativa que o sujeito dá significado a sua história e planeja suas ações futuras. A identidade, como espaço de construção do sujeito psicológico parece ser um lócus privilegiado onde podemos observar o funcionamento do paradigma narrativo em termos de negociação de significados entre os acontecimentos históricos/biográficos e o modo como o sujeito os significa. A introdução da noção vygotskyana de processo articulada em uma perspectiva histórica, na qual o fenômeno psicológico só pode ser compreendido a partir de seu processo de construção histórica, pode ser aplicada à perspectiva da construção relacional da identidade narrativa (Botella, 2007) ou do self narrativo (Gergen \& Warhuus, 2007) na investigação da relação entre realidade e linguagem, tal como problematizada pelo paradigma narrativo (Gonçalves \& Gonçalves, 2007). Nesta perspectiva, cada processo tem de ser visto de forma individualizada, no sentido de que cada sujeito ocupa determinadas posições históricas ou desempenha determinados papéis ao longo de sua história, os quais se organizam em um processo de desenvolvimento que delimita o campo interpretativo de seu entendimento e define a sua versão narrativa da história de vida. Essa dialética entre indivíduo e contexto historicamente situado parece ser fundamental para a compreensão de como o sujeito constrói significados a 
Vieira, A. G. \& Henriques, M. R. (2014). A Construção Narrativa da Identidade.

partir da realidade vivida, principalmente se tivermos em consideração que essa construção se dá no entrelaçamento de diferentes posições do self em diferentes cenários e em uma antologia de histórias de vida que se complementam na organização de uma identidade.

\section{Referências}

Adler, J. M., \& McAdams, D. P. (2007). Time culture, and stories of the self. Psychological Inquiry, 18(2), 97-128.

Bakhtin, M. (1973). Problems of Dostoevsky poetics. Ann Arbor, MI: Ardis.

Bernsten, D., \& Rubin, D. C. (2004). Cultural life scripts structure recall from autobiographical memory. Memory \& Cognition, $32,27-42$.

Botella, L. (2007). Diálogo, relações e mudança: Uma aproximação discursiva à psicoterapia construtivista. In M. M. Gonçalves \& Ó. F. Gonçalves (Eds.), Psicoterapia, discurso e narrativa: A construção conversacional da mudança (pp. 93-124). Coimbra, Portugal: Quarteto.

Brockmeier, J., \& Harré, R. (2003). Narrativas: Problemas e promessas de um paradigma alternativo. Psicologia: Reflexão e Crítica, 16(3), 525-535.

Bruner, J. (1987). Life as narrative. Social Research, 54(1), 11-32.

Bruner, J. (1997). Atos de significação. Porto Alegre, RS: Artes Médicas.

Delory-Momberger, C. (2004). Biographie, socialisation, formation: comment les individus deviennent-ils des individus? L'orientation Scolaire et Professionnelle, 33(4), 2-17.

Erikson, E. H. (1968). Youth and identity. New York: Norton.

Fivush, R. (2008). Remembering and reminiscing: How individual lives are constructed in family narratives. Memory Studies, 1(1), 49-58.

Fivush, R., \& Baker-Ward, L. (2005). The search for meaning: Developmental perspectives on internal state language in autobiographical memory. Journal of Cognition and Development, 6(4), 455-462.

Fivush, R., \& Buckner, J. P. (1998). Gender and self in children's autobiographical narratives. Applied Cognitive Psychology, 12, 407-429.

Fivush, R., \& Haden, C. A. (2003). Autobiographical memory and the construction of a narrative self: Developmental and cultural perspectives. Mahwah, NJ: Lawrence Erlbaum.

Gergen, K., \& Warhuus, L. (2007). Terapia como construção social: Características, reflexões e evoluções. In M. M. Gonçalves \& Ó. F. Gonçalves (Eds.), Psicoterapia, discurso e narrativa: A construção conversacional da mudança (pp. 29-65). Coimbra, Portugal: Quarteto.

Giddens, A. (1991). Modernity and self-identity. Stanford, CA: Stanford University Press.

Gonçalves, M., \& Gonçalves, Ó. (2007). A psicoterapia como construção conversacional. In M. M. Gonçalves \& Ó. F. Gonçalves (Eds.), Psicoterapia, discurso e narrativa: $A$ construção conversacional da mudança (pp. 11-28). Coimbra, Portugal: Quarteto.

Habermas, T. (2007). How to tell a life: The development of the cultural concept of biography. Journal of Cognition and Development, 8(1), 1-31.

Habermas, T., \& Bluck, S. (2000). Getting a life: The emergence of the life story in adolescence. Psychological Bulletin, 126(5), 748-769
Habermas, T., Ehlert-Lerche, S., \& de Silveira, C. (2009). The development of the temporal macroestructure of life narratives across adolescence: Beginnings, linear narrative form, and endings. Journal of Personality, 77(2), 527-559.

Hermans, H. (2001). The dialogical self: Toward a theory of personal and cultural positioning. Culture \& Psychology, 7(3), 243-281.

Hermans, H. J. M. (2008). How to perform research on the basis of dialogical self theory? introduction to special issue. Journal of Constructivist Psychology, 21, 185-199.

Hermans, H. J. M., \& Kempen, H. J. G. (1993). Imaginal dialogues in the self: Theory and method. Journal of Personality, 61(2), 207-236.

Hooker, K. \& McAdams, D. P. (2003). Personality reconsidered: A new agenda for aging research. Journal of Gerontology: Psychological Sciences, 58(6), 296-304.

James, W. (1890). The principles of psychology (Vol. 1). London: Macmillan.

Jung, C. G. (1995). Estudos experimentais. Petrópolis, RJ: Vozes. (Original publicado em 1909)

Kant, I. (1985). Crítica da razão pura. Lisboa, Portugal: Gulbenkian. (Original publicado em 1781)

Markus, H., \& Wurf, E. (1987). The dynamic self concept: A social psychological perspective. Annual Review of Psychology, 38, 299-337.

Martindale, C. (1980). Subselves: The internal representation of situational and personal dispositions. In L. Wheeler (Ed.), Review of personality and social psychology (pp. 193-218). Beverly Hills, CA: Sage.

McAdams, D. P. (1985). Power, intimacy and the life story: Personological inquiries into identity. New York: Guilford Press.

McAdams, D. P. (1993). The stories we live by: Personal myths and the making of the self. New York: The Guilford Press.

McAdams, D. P. (2001). The psychology of life stories. Review of General Psychology, 5(2), 100-122.

McAdams, D. P. (2004). The redemptive self: narrative identity in America today. In D. R. Beike, J. M. Lampien, \& D. A. Behrend (Eds.), The self and memory (pp. 95-115). New York: Psychology Press.

McAdams, D. P. (2005). What psychobiographers might learn from personality psychology. In W. T. Schultz (Ed.), Handbook of psychobiography (pp. 64-83). Oxford, UK: Oxford University Press.

McAdams, D. P. (2006). The redemptive self: Generativity and the stories Americans live by. Research in Human Development, 3(2), 81-100.

McLean, K. C., Pasupathi, M., \& Pals, J. L. (2007). Selves creating stories creating selves: A process model of selfdevelopment. Personality and Social Review, 11, 262-278.

Mead, G. H. (1934). Mind, self and society. Chicago, IL: University of Chicago Press.

Murray, H. A. (1938). Explorations in personality. New York: Oxford University Press.

Pasupathi, M. (2001). The social construction of the personal past and its implications for adult development. Psychological Bulletin, 127(5), 651-672.

Ricoeur, P. (1994). Tempo e narrativa. Campinas, SP: Papirus. Salgado, J., \& Hermans, H. (2005). The return of subjectivity: From a multiplicity of selves to the dialogical self. E-Journal of Applied Psychology: Clinical Section, 1(1), 3-13.

Sennett, R. (2000). Le travail sans qualitiés: les consequences humaines de la flexibilité. Paris, France: Albin Michel. 
Tomkins, S. S. (1979). Script theory. In H. E. Howe Jr. \& R. A. Dienstbier (Eds.), Nebraska symposium on motivation (pp. 201-236). Lincoln, NE: University of Nebraska Press.

Valsiner, J. (1989). Human development and culture: The social nature of personality and its study. Lexington, MA: Lexington Books.

Valsiner, J. (2002). Forms of dialogical relations and semiotic autoregulation within the self. Theory and Psychology, 12(2), 251-265.

Vygotsky, L. S. (1991). A formação social da mente. São Paulo, SP: Martins Fontes.

Vygotsky, L. S. (2000). Lev S. Vigostski: Manuscrito de 1929. Educação \& Sociedade, 71, 21-44. (Original publicado em 1929)

Wertsch, J. V., Del Rio, P., \& Álvarez, A. (1995). Sociocultural studies of mind. New York: Cambridge University Press.

Wittgenstein, L. (1991). Investigações filosóficas. São Paulo, SP: Nova Cultural. 